\title{
A quantitative trait locus analysis of seed production traits in perennial ryegrass (Lolium perenne L.)
}

\author{
AM Sartie $^{1}$, H S Easton ${ }^{1}$, C Matthew ${ }^{2}$ and M J Faville ${ }^{1}$ \\ ${ }^{1}$ AgResearch Ltd., Grasslands Research Centre, Private Bag 11008, Palmerston North, \\ New Zealand \\ ${ }^{2}$ Institute of Natural Resources, Massey University, Private Bag 11222, Palmerston \\ North, New Zealand
}

Abstract. A full-sib mapping population $(\mathrm{n}=188)$ from a cross between cultivars 'Grasslands Impact' and 'Grasslands Samson' was used to identify quantitative trait loci (QTL) controlling seed yield and component traits in perennial ryegrass. Thirteen traits, including seed yield per plant (SYP) and five seed yield components (number of spikes (SP), spikelets per spike (SS), florets per spikelet (FSP), seed weight (SW) and floret site utilisation (FSU)), seed yield per spike (SYH) and seven other seed yield-associated traits, were phenotypically assessed in a replicated spaced plant field experiment. Interval mapping identified 35 QTL for all traits but one, spanning all linkage groups (LG). Multiple QTL were detected for most traits. QTL for SYP and component traits, as well as some seed yield-associated traits, co-located to the same genomic regions on LG 1, 2 and 6. Markers associated with these regions, in particular, will form the basis for the on-going development of MAS tools for improvement of seed yield and quality in breeding programmes. Further development will require refinement of QTL positions and effects using multiple QTL mapping (MQM), and validation of QTL and associated markers in other genetic backgrounds and environments.

\section{Introduction}

Seed yield is an important factor in the commercial success of perennial ryegrass (Lolium perenne L.) cultivars. However, seed yield can be unreliable (Elgersma 1990), depending on season, location and cultivar, and its improvement through artificial selection is problematic (van Wijk and Duyvendak 1984), partly because it is the product of several component traits which are strongly influenced by environmental factors. These component traits include: number of spikes per plant (SP), number of florets per spike (FS), seed weight (SW) and floret site utilisation (FSU) (Elgersma 1990; Martins 1990). Seed yield per plant (SYP) is the product of SP x seed yield per spike (SYH), where SYH = Spikelets per spike (SS) x florets per spikelet (FSP) x FSU $x$ SW. In contributing toward seed yield, SP determines the number of reproductive tillers, FSP, FS and FSU are co-determinants of the potential number of seeds per spike (often with compensation occurring between them). SW is a measure of seed size (which influences seed vigour).

Improvement of seed production may be accelerated by developing markerassisted selection (MAS) tools for seed yield and its component traits, enabling precise and early selection of superior plants using genetic testing. This paper describes the detection of QTL for seed yield and its component traits in perennial ryegrass, and represents the first stage in the development of MAS tools for seed production.

\section{Materials and methods}

A full-sib $\mathrm{F}_{1}$ mapping population ( $\left.\mathrm{n}=188\right)$, (IxS), generated by pair-crossing plants from cultivars 'Grasslands Impact'(I) and 'Grasslands Samson'(S), was planted in a 
replicated $(\mathrm{n}=4)$ spaced plant field experiment (Randomised Complete Block) at Palmerston North in July 2003. Phenotypic assessment of the mapping population and its parents was conducted for 13 traits, including SYP and four components (SP, FS, SW and FSU), SYH and seven other seed yield associated traits: days to heading (DH), spread of heading within a plant ( $\mathrm{SOH})$, plant growth habit (PGH), number of tillers with matured spikes (TMH), spike length (SL), spikelets per spike (SS), and florets per spikelet (FSP). Data for DH, SOH and PGH were collected in the field in November December 2003. Data on SL, SS and FSP were obtained on three spikes randomly harvested from each plant in every block seven weeks after heading. Seed material was harvested from December 2003 through to January 2004, and SP and TMH were measured before seed threshing, after drying at room temperature. SYP and SW (measured as 1000 seed weight, TSW) were measured after seeds were cleaned to TSW of over 1.3g. SYH was calculated as FS x TSW, FSU was calculated as SYP / (SP x SW $x$ FS) and FS was calculated as the average number of florets on spikelets at the bottom, middle and top of spikes multiplied by the average number of spikelets on three randomly selected spikes Analyses of variance were performed using GenStat version 8.1 (GenStat 2005). Broad sense heritability estimates were calculated as $\mathrm{H}_{\mathrm{b}}=\sigma^{2} \mathrm{~g} /($ $\left.\sigma^{2} \mathrm{~g}+\left(\sigma^{2} \mathrm{e} / \mathrm{r}\right)\right)$ where $\sigma^{2} \mathrm{~g}=$ genotypic component of variance, $\sigma^{2} \mathrm{e}=$ residual variance of means of genotypes and $\mathrm{r}=$ number of replications (Burton et al. 1953). A genetic linkage map for population IxS was constructed using JoinMap ${ }^{\circledR} 3.0$

(http://www.kyazma.nl/), with 165 EST-SSR markers (simple sequence repeat markers derived from expressed sequence tags). Marker PCR and genotyping were conducted as in Faville et al. (2004). QTL were detected by interval mapping using MapQTL ${ }^{\circledR} 4.0$ software (http://www.kyazma.nl/). Permutation testing $(\mathrm{n}=1000)$ established a logarithm-of-odds (LOD) threshold for each trait, for declaration of a QTL at a chromosome-wide significance of $\alpha=0.05$.

\section{Results and discussion}

Within the IxS mapping population, plants were significantly $(P<0.01)$ different for all traits, and there were significant differences between parents also $(P<0.05$, Table 1). Broad sense heritability values ranged from 0.27 for SS, up to 0.94 for DH and FSU (Table 1). These data confirm genetic variation in all of the assessed traits, and the values observed are comparable with earlier heritability estimates for reproductive traits in perennial ryegrass (Elgersma 1990b; Yamada et al. 2004).

Linkage analysis using 165 EST-SSRs located 164 loci on seven linkage groups (LG) in the IxS map (Figure 1), with assignments consistent with other ryegrass maps (Faville et al. 2004). This map is 588 Kosambi centimorgans long, with a locus every $3.6 \mathrm{cM}$ on average.

Interval mapping identified 35 QTL for all traits except TMH, with between one and four QTL identified per trait (Figure 1, Table 2). QTL for SYP and its component traits were identified at the same genomic regions on LG 1,2 and 6. The three QTL for SYP collectively accounted for $35 \%$ of phenotypic variation (PVE) of the trait in the population, with the QTL on LG 6 having the highest LOD score and \% PVE (Table 2). Coincident QTL for seed yield component traits SS, FSU and SW, as well as for the related traits SYH and FS, were detected at the same sites on LG 1 (FSU, SS, SYH), 2 (FS, FSP, SW, SYH) and 6 (FSU, SS, SW, SYH). These co-locations reflect the causal relationship between these traits. Additional QTL, one each for SW, FS and FSP and two for FSU were identified on LG 3, 4 and 5 accounting for $18.7 \%, 9 \%, 11 \%$ and 
$20.7 \%$ PVE, respectively, and an additional QTL for SYH (9.5\% PVE) was detected on LG 5 (Table 2).

Table 1. Mean, range, SE of a genotype mean and broad sense heritability $\left(\mathrm{H}_{\mathrm{b}}\right)$ of 188 IxS mapping population genotypes, and the two parents, for seed yield and component traits in perennial ryegrass.

\begin{tabular}{|l|c|c|c|c|c|c|}
\hline Trait & Mean & Range & $\begin{array}{c}\text { Samson } \\
\text { parent }\end{array}$ & $\begin{array}{c}\text { Impact } \\
\text { parent }\end{array}$ & SE & $\mathbf{H}_{\mathbf{b}}$ \\
\hline SYP & 35.25 & $11.95-64.48$ & 27.65 & 11.95 & 5.11 & 0.75 \\
\hline DH & 126.3 & $113-136$ & 118 & 136 & 0.93 & 0.94 \\
\hline FS & 226 & $162-298$ & 224 & 162 & 21.6 & 0.33 \\
\hline FSP & 8 & $7-11$ & 8 & 7 & 0.6 & 0.33 \\
\hline FSU & 0.223 & $0.089-0.416$ & 0.255 & 0.313 & 0.039 & 0.94 \\
\hline PGH & 3.3 & $1.0-7.0$ & 1 & 7 & 0.49 & 0.77 \\
\hline SP & 391.6 & $184-592$ & 272 & 184 & 51.04 & 0.59 \\
\hline SL & 19.63 & $16.13-23.60$ & 19 & 19.77 & 0.948 & 0.39 \\
\hline SOH & 6.6 & $2.0-13.0$ & 13 & 7 & 1.08 & 0.58 \\
\hline SS & 27 & $21-31$ & 29 & 23 & 1.4 & 0.27 \\
\hline SYH & 91.95 & $46.74-169.62$ & 103.63 & 65.06 & 10.845 & 0.75 \\
\hline TMH & 326 & $165-528$ & 225 & 165 & 44.6 & 0.62 \\
\hline SW & 1.9 & $1.35-2.48$ & 2.08 & 1.35 & 0.067 & 0.76 \\
\hline
\end{tabular}

$\mathrm{SYP}=$ seed yield per plant $(\mathrm{g}) ; \mathrm{DH}=$ days to heading from time of transplanting in the field; FS= floret per spike; FSP= floret per spikelet; FSU= floret site utilization; $\mathrm{PGH}=$ plant growth habit; $\mathrm{SP}=$ spikes per plant; $\mathrm{SL}=$ spike length $(\mathrm{cm}) ; \mathrm{SOH}=$ spread of heading (days); $\mathrm{SS}=$ spikelets per spike; $\mathrm{SYH}=$ seed yield per spike (mg); $\mathrm{TMH}=$ matured spikes per plant; SW=1000 seed weight (g).

For other associated traits, QTL for SYP co-located with QTL for SL on LG 1 and 2, and with DH and PGH on LG 2. For these traits, co-location of QTL may indicate either a causal relationship between traits, or allelic variation at a single pleiotropic locus, or a number of linked loci within the QTL region (Yamada et al. 2004). These alternatives cannot be definitively resolved with this QTL data set; nonetheless, molecular markers associated with QTL co-locating to regions on LG 1 , LG 2 and LG 6, in particular, are clearly promising candidates for the further development of genetic selection tools for the improvement of seed production characteristics.

The numbers, precise location and magnitude of effect of QTL identified here have yet to be refined using multiple QTL mapping (MQM) analysis, but the current analysis affords a first insight into the location and relative contributions of genetic factors underlying a comprehensive suite of seed production traits in perennial ryegrass. Future work will include MQM analysis of the current data set, as well as validation of QTL, and associated markers, in different genetic backgrounds and environments, and assessment of their effectiveness in plants grown in sown plots, as opposed to the spaced plant format used here.

\section{Acknowledgment}

This work was sponsored by a Bright Futures Enterprise Scholarship, funded by the Tertiary Education Commission of New Zealand and Agricom New Zealand Ltd. 
Figure 1: Perennial ryegrass genetic linkage map showing QTL detected for seed yield components and associated traits. Linkage groups LG 1 to LG7 show marker names at left of bars, QTL positions and names (refer to Table 1) at right of the bars, and length of linkage groups in centimorgans at the foot of the bars.

LG1

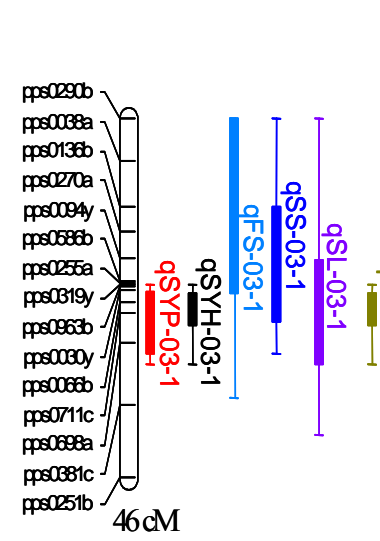

LG2

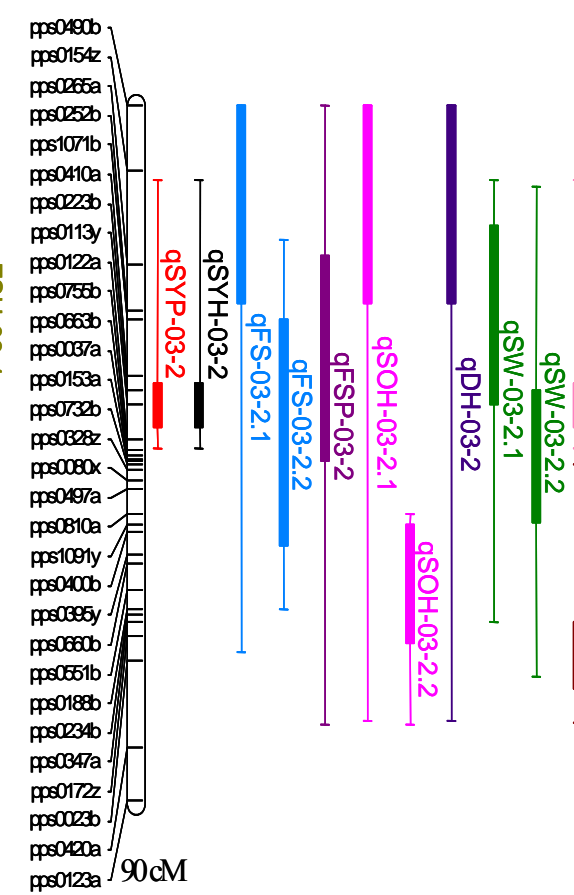

LG3

LG4

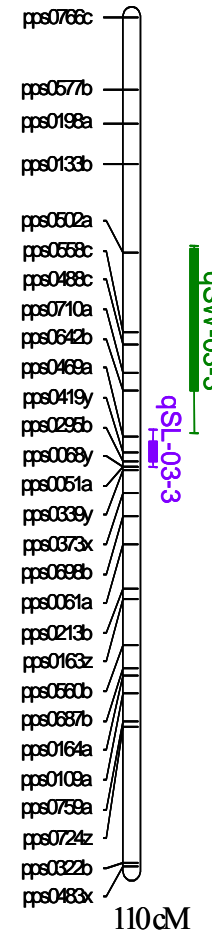

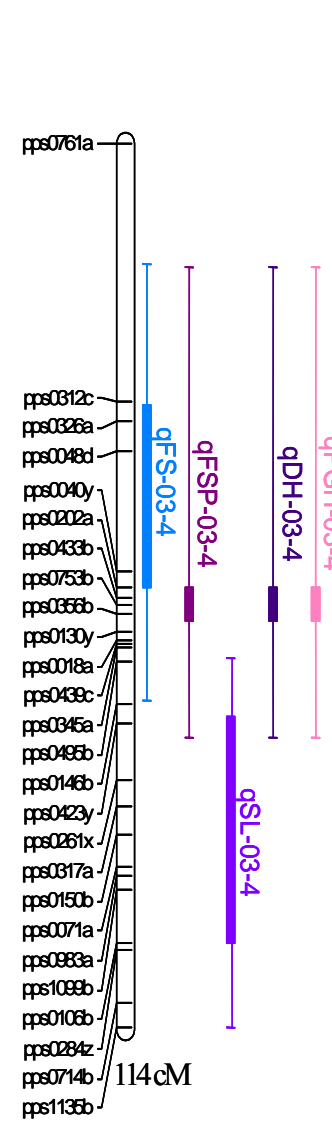

LG5

LG6

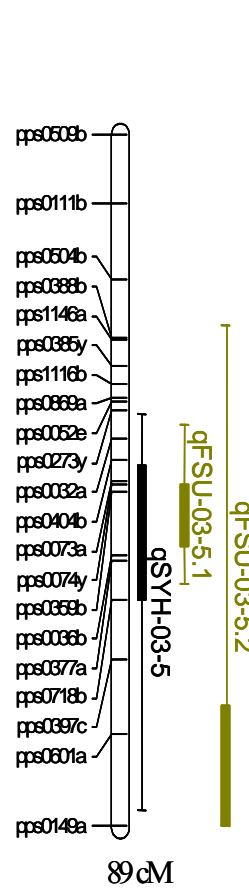

pposocosb

pos0132a

posomis

posolizat

prof4azi

prosorza

prosionta

procenca

ppo5092b

pposcisa

年

procoseza

70

posconab $45 \mathrm{cM}$

$\cos 8$

procose $x$

pro40450a

posc6zas
LG

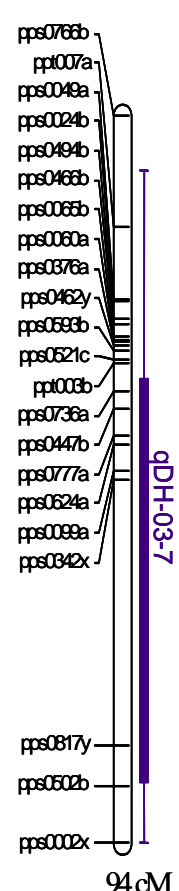


Table 2. Quantitative trait loci for seed yield and component traits in perennial ryegrass. Trait abbreviations are given in the main text and with Table 1. LOD threshold indicates QTL significance (chromosome-wide), and was determined by permutation testing $(n=1000) . L G=$ linkage group; $P V E=$ phenotypic variance attributable to QTL.

\begin{tabular}{|c|c|c|c|c|c|c|}
\hline Trait & LG & QTL & $\begin{array}{l}\text { Maximum LOD } \\
\text { position } \\
(\mathrm{cM})\end{array}$ & $\begin{array}{l}\text { LOD } \\
\text { threshold }\end{array}$ & $\begin{array}{l}\text { Maximum } \\
\text { LOD } \\
\text { value }\end{array}$ & PVE (\%) \\
\hline \multirow[t]{3}{*}{ SYP } & 1 & qSYP-03-1 & 28.2 & 2.63 & 3.44 & 8.7 \\
\hline & 2 & qSYP-03-2 & 38.6 & 2.77 & 3.88 & 9.6 \\
\hline & 6 & qSYP-03-6 & 19.9 & 2.70 & 6.49 & 16.8 \\
\hline \multirow[t]{4}{*}{ SYH } & 1 & qSYH-03-1 & 24.9 & 2.48 & 3.01 & 7.6 \\
\hline & 2 & qSYH-03-2 & 38.6 & 2.95 & 3.57 & 8.9 \\
\hline & 5 & qSYH-03-5 & 54.4 & 2.85 & 3.68 & 9.5 \\
\hline & 6 & qSYH-03-6 & 19.9 & 2.70 & 10.25 & 25.3 \\
\hline \multirow[t]{4}{*}{ FS } & 1 & qFS-03-1 & 17.3 & 2.39 & 3.97 & 10.5 \\
\hline & 2 & qFS-03-2.1 & 8.4 & 2.82 & 3.45 & 10.4 \\
\hline & 2 & qFS-03-2.2 & 43.2 & 2.82 & 3.92 & 10.3 \\
\hline & 4 & qFS-03-4 & 39.8 & 2.81 & 3.51 & 9.0 \\
\hline \multirow[t]{3}{*}{ SS } & 1 & qSS-03-1 & 17.3 & 2.58 & 3.95 & 10.6 \\
\hline & 6 & qSS-03-6.1 & 0.0 & 2.61 & 3.78 & 15.3 \\
\hline & 6 & qSS-03-6.2 & 32.7 & 2.61 & 3.75 & 9.6 \\
\hline \multirow[t]{2}{*}{ FSP } & 2 & qFSP-03-2 & 43.2 & 2.94 & 3.61 & 9.5 \\
\hline & 4 & qFSP-03-4 & 60.7 & 3.00 & 4.12 & 11.0 \\
\hline \multirow[t]{3}{*}{ SL } & 1 & qSL-03-1 & 22.5 & 2.43 & 3.31 & 8.3 \\
\hline & 3 & qSL-03-3 & 56.2 & 2.90 & 8.99 & 21.0 \\
\hline & 4 & qSL-03-4 & 94.6 & 2.92 & 3.17 & 9.7 \\
\hline \multirow[t]{4}{*}{ FSU } & 1 & qFSU-03-1 & 24.9 & 2.40 & 3.36 & 8.4 \\
\hline & 5 & qFSU-03-5.1 & 46.2 & 2.71 & 4.17 & 11.4 \\
\hline & 5 & qFSU-03-5.2 & 89.3 & 2.71 & 2.99 & 9.3 \\
\hline & 6 & qFSU-03-6 & 11.5 & 2.78 & 5.23 & 12.9 \\
\hline \multirow[t]{2}{*}{$\mathrm{SOH}$} & 2 & qSOH-03-2.1 & 8.4 & 2.79 & 3.51 & 8.8 \\
\hline & 2 & qSOH-03-2.2 & 65.8 & 2.79 & 3.63 & 9.4 \\
\hline \multirow[t]{3}{*}{$\mathrm{DH}$} & 2 & qDH-03-2 & 8.4 & 2.90 & 11.46 & 28.2 \\
\hline & 4 & qDH-03-4 & 60.7 & 2.74 & 6.94 & 17.5 \\
\hline & 7 & qDH-03-7 & 42.5 & 2.74 & 3.18 & 8.4 \\
\hline \multirow[t]{4}{*}{ SW } & 2 & qSW-03-2.1 & 20.6 & 3.00 & 4.12 & 15.2 \\
\hline & 2 & qSW-03-2.2 & 49.4 & 3.00 & 4.25 & 11.3 \\
\hline & 3 & qSW-03-3 & 42.3 & 2.92 & 7.20 & 18.7 \\
\hline & 6 & qSW-03-6 & 18.5 & 3.80 & 3.93 & 9.9 \\
\hline \multirow[t]{2}{*}{ PGH } & 2 & qPGH-03-2 & 38.6 & 3.04 & 5.58 & 13.6 \\
\hline & 4 & qPGH-03-4 & 60.7 & 2.96 & 5.99 & 15.2 \\
\hline SP & 2 & qSP-03-2 & 71.8 & 2.30 & 3.09 & 7.8 \\
\hline
\end{tabular}




\section{References}

Burton GW and DeVane EH (1953) Estimating heritability in tall fescue (Festuca arundinacea) from replicated clonal material. Agronomy Journal 45, 478-481.

Elgersma A (1990) Seed yield related to crop development and to yield components in nine cultivars of perennial ryegrass (Lolium perenne L.). Euphytica 49, 141154.

Elgersma A (1990b) Heritability estimates of spaced-plants traits in three perennial ryegrass (Lolium perenne L) cultivars. Euphytica 51, 163-171.

Faville MJ, Vecchies AC, Schreiber M, Drayton MC, Hughes LJ, Jones ES, Guthridge KM, Smith KF, Sawbridge T, Spangenberg GT, Bryan G and Forster JW (2004) Functionally-associated molecular genetic marker map construction in perennial ryegrass (L. perenne L.). Theoretical and Applied Genetics 110, 12-32.

GenStat (2005) GenStat for Windows. Release 8.1. Eight Edition. VSN International Ltd., Oxford.

Martins VMM. (1990). The effect of plant growth regulators on floret dynamics and seed production of perennial ryegrass (Lolium perenne L.). Faculty of graduate studies. Guelph, The University of Guelph. PhD Thesis.

Yamada T, Jones ES, Cogan NOI, Vecchies AC, Nomura T, Hisana H, Shimamoto Y, Smith KF, Hayward MD and Forster JW (2004). QTL analysis of morphological, developmental, and winter hardiness-associated traits in perennial ryegrass. Crop Science 44, 925-935.

van Wijk AJP and Duyvendak R (1984). Constraints in grass breeding with particular reference to perennial ryegrass (Lolium perenne L.). In "Development, construction and multiplication of fodder crop varieties". Report of the fodder crops section of Eucarpia, Freising-Weihenstephan, F.R.G., 147-156. 